\title{
A numerical simulation of the combustion processes of wood pellets
}

\author{
J. Ahn ${ }^{1} \&$ H. J. Kim ${ }^{2}$ \\ ${ }^{I}$ School of Mechanical Systems Engineering, Kookmin University, Korea \\ ${ }^{2}$ Korea Institute of Energy Research, Korea
}

\begin{abstract}
Combustion processes of wood pellets in hot cross flows have been studied on the basis of a series of unsteady simulations. Results show that the pellet ignition occurs with a cross flow temperature higher than $600^{\circ} \mathrm{C}$. The locus of the ignition point changes depending on the free stream temperature, while combustion of char occurs throughout the pellet for all investigated temperatures. The total combustion time in addition to the time required for volatile materials to decrease occurs more rapidly with inlet temperature changes from $600^{\circ} \mathrm{C}$ to $700^{\circ} \mathrm{C}$ than that from $700^{\circ} \mathrm{C}$ to $800^{\circ} \mathrm{C}$.
\end{abstract}

Keywords: wood pellet, combustion, Computational Fluid Dynamics (CFD).

\section{Introduction}

Greenhouse gases with high global warming potential, such as methane, are produced from wood that has decomposed in the ground; thus, wood is considered to be a new recycled heat resource. A combustion system that takes advantage of this process is popular mainly in developed countries, including Europe. When wood waste is directly combusted, combustion efficiency and controllability are low, and dust and exhaust gas are emitted; hence, pre-processing is usually performed to achieve effective combustion. Although gasification and liquefaction can be performed for pre-processing, these methods are costly and thus are economically disadvantageous. Wood pellet combustion minimizes pre-process expenses by adopting physical processes, such as grinding, drying and sintering, and is therefore suggested as a reasonable alternative [1-4]. 
For the combustion of wood pellets, several methods used in coal combustion are adopted that include the Stoker, fluidized bed, and rotary Kiln methods. Moreover, an additional technique has recently been implemented that includes development of a customized burner that improves controllability. In this method, the wood pellet passes through a complex combustion process accompanied by thermal degradation - or thermopyrolysis - and phase changes, as in other solid fuels. Therefore, to develop a combustor for wood pellets, knowledge of wood pellet parameters such as ignition and combustion time, depending on atmospheric temperature or oxygen concentration, is required $[4,5]$.

In the present study, unsteady numerical simulation for combustion phenomena, according to atmospheric temperature, was performed for wood pellets to be used as fuel for under-developing-boiler working with the Stoker combustion method. The ignition properties and combustion processes of wood pellets according to atmospheric temperature were addressed by adopting the combustion simulation method [6-9] for woody fuel composed of cellulose and lignin that accompanies thermal degradation and phase changes on the surface.

\section{Numerical method}

In the present study, unsteady numerical simulation was performed to observe physical phenomena that occur during combustion processes in which pellets are combusted by the introduction of hot air to $0.9 \mathrm{~g}$ of wood pellets, as shown in Fig. 1. The wood pellets used in this study were domestically produced and included properties of $4,550 \mathrm{kcal} / \mathrm{kg}$ high heating value and $8.28 \%$ moisture. The flux of the introduced hot air was fixed at $12.35 \mathrm{~m}^{3} / \mathrm{h}$ according to an experiment performed in a prior study [4]. The temperatures of hot air were $500^{\circ} \mathrm{C}, 600^{\circ} \mathrm{C}$, $700^{\circ} \mathrm{C}$ and $800^{\circ} \mathrm{C}$, and combustion time and form of the pellet frame were analyzed at each temperature.

The computational domain was set as that of a quartz tube containing pellets, which corresponds to the test section in basic combustion experiments. Two-dimensional simulation was conducted due its axi-symmetric form. The boundary conditions at the inlet included a hot air flux of $12.35 \mathrm{~m}^{3} / \mathrm{h}$. Temperature and oxygen mass fractions corresponded to those in simulation conditions, and for the wall and outlet, no respective slip or adiabatic conditions were applied. The grid system was Cartesian of which grids were mainly positioned near pellets and were extended to upstream and downstream. Downstream grids where combustion phenomena occurred was constituted to be finer than those upstream.

For simulation of the present study, the commercially available FLUENT software program was used. Continuity, incompressible momentum equation, and energy equation were simulated with the governing equation. Woody fuel accompanies thermal degradation and phase changes on the surface and is composed of cellulose and lignin; thus, a model to reflect these characteristics was needed. However, because such a model is beyond the capabilities of FLUENT, a development for a user-defined function was required. In the present 
study, such a function was developed by investigating the prior documents related to conventional woody fuel combustion [6-9] and researching the numerical simulation method, which is adequate for wood pellets.

Table 1: Composition analysis of the wood pellets used in this study (wt\%).

\begin{tabular}{|c|c|c|c|}
\hline \multicolumn{2}{|c|}{ Proximate Analysis } & \multicolumn{2}{c|}{ Ultimate Analysis } \\
\hline Moisture & 8.3 & $\mathrm{C}$ & 48.8 \\
\hline Volatile Matter & 73.7 & $\mathrm{H}$ & 6.9 \\
\hline Fixed Carbon & 17.9 & $\mathrm{O}$ & 43.5 \\
\hline Ash & 0.1 & $\mathrm{~N}$ & 0.4 \\
\hline
\end{tabular}

Because the wood pellets were assumed to consist of solid and porous parts, effective thermal conductivity was defined on the basis of their porosity to consider the effect of the gas and solid components in the calculation of thermal conduction [9]. The mass of the combustion material can be expressed through Eqn (1), where initial porosity is $\alpha$.

$$
\begin{gathered}
\mathrm{m}_{\text {comb }}=\alpha \mathrm{m} \\
\frac{\mathrm{dm}_{\mathrm{w}}}{\mathrm{dt}}=\mathrm{m}_{\mathrm{w}} \mathrm{A}_{1} \exp \left(-\frac{\mathrm{E}_{1}}{\mathrm{RT}}\right) \\
\frac{\mathrm{dm}_{\mathrm{v}}}{\mathrm{dt}}=\mathrm{m}_{\mathrm{v}} \mathrm{A}_{2} \exp \left(-\frac{\mathrm{E}_{2}}{\mathrm{RT}}\right)
\end{gathered}
$$

Modeling of thermal degradation and the combustion process of the wood pellets was performed on the basis of their thermal degradation products, which include gas, tar, and char. Because inner temperature is increased by the conduction of heat from outside of the pellet surface, the inner temperature of the pellet increases until the water vapor reaches saturation, wherein latent heat of the water is considered (Eqn (2)). When water is vaporized, the inner temperature of pellet increases; thus, volatile matter is also vaporized, wherein latent heat of the volatile components is considered (Eqn (3)). The char that remains after removal of such moisture and volatile matter is combusted by the surrounding air.

\section{Results and discussion}

The velocity field obtained through numerical simulation exhibited a constant inlet flux, or mass flow rate; thus, no significant differences were observed in inlet temperature despite differences in combustion processes. Considering the velocity vector suggested in Fig. 1, an overall formation of external flow around solid pellets was observed. The pellets exhibited a high aspect ratio, small entire area, and relatively low Reynolds number; thus, although lowvelocity sections were observed at particular areas, a recycle region apparently did not form at the latter parts of the pellets. The retention time of volatiles in these low-velocity sections of the latter parts became longer and were subjected to more contact time with hot air; thus, attachment of flame was expected. 

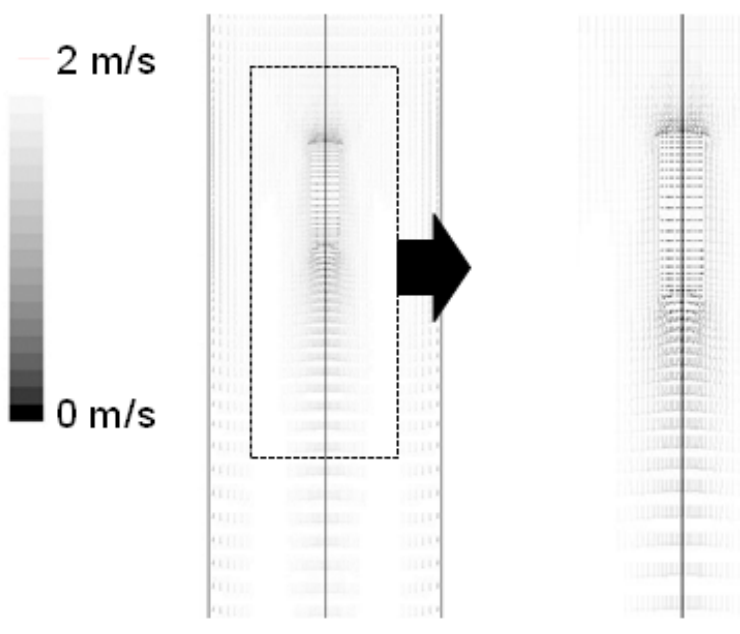

Figure 1: Velocity vectors from computational fluid dynamics (CFD).

Ignition did not occur when the air temperature at the inlet was set at $500^{\circ} \mathrm{C}$; however, ignition was observed after $74 \mathrm{~s}$ when air temperature was $600^{\circ} \mathrm{C}$ (Figs. 2(a), (b)). When ignition did occur, high temperatures were observed throughout the pellets. The region of highest temperature, which was expected to be a locus of flame, was positioned at the latter parts of pellets. After $199 \mathrm{~s}$, combustion of volatile components was completed by the progress of ignition (Fig. 2(c)). Around this time, combustion was observed mainly at the front parts of the pellets. After 395 s, combustion of char was completed (Fig. 2(d)). In this case, uniform combustion was observed throughout the pellets.

When hot air temperature was $700^{\circ} \mathrm{C}$, ignition was observed after $12 \mathrm{~s}$ (Figs. 3(a), (b)). When ignition occurred, the high-temperature region was distributed throughout the pellets; the highest temperature was observed at the latter parts of pellets, similar to that observed in case of $600^{\circ} \mathrm{C}$. After $68 \mathrm{~s}$, the combustion of volatiles was completed (Fig. 3(c)). Unlike in that observed in the case of $600^{\circ} \mathrm{C}$, however, (Fig. 2), combustion of volatile matter was completed by the progress of ignition at approximately the same time as combustion was observed throughout the pellets. After 249 s (Fig. 3(d)), the combustion of char was completed, which was uniformly distributed throughout the pellets.

When the air temperature at the inlet was increased to $800^{\circ} \mathrm{C}$, ignition was observed after 3 s (Figs. 4(a), (b)). When ignition occurred, the high-temperature area formed after the latter parts of pellets, and the highest temperature was positioned at right after the latter parts, unlike that observed in the cases of $600^{\circ} \mathrm{C}$ and $700^{\circ} \mathrm{C}$. After $60 \mathrm{~s}$ (Fig. 4(c)), the combustion of volatile components was completed and occurred throughout the pellets, similar to that observed in the case of the $700^{\circ} \mathrm{C}$ inlet temperature. The combustion of char was completed after 202 s (Fig. 4(d)), and uniform combustion was observed throughout the pellets, as was reported in the prior experiments. 
(a)

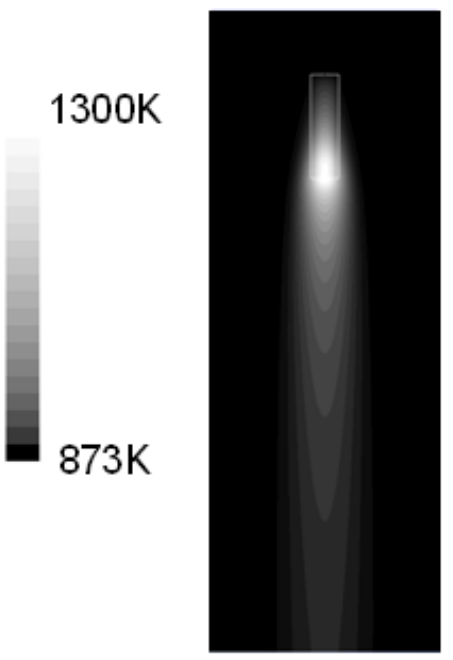

(c)

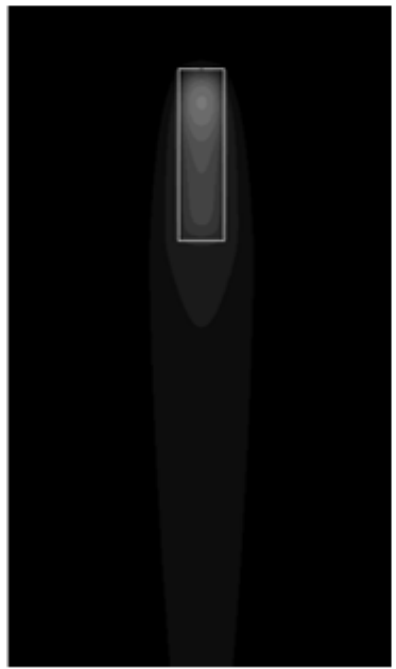

(b)

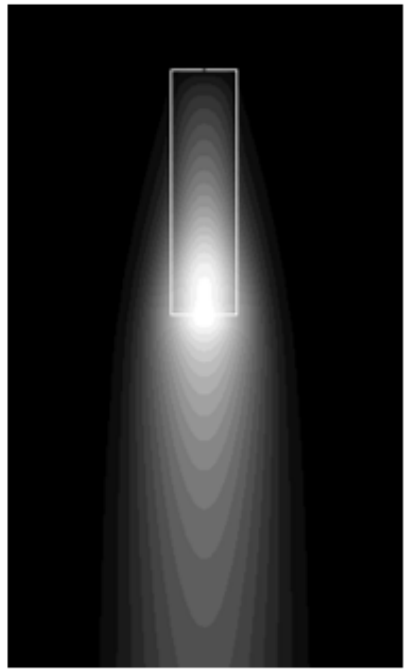

(d)

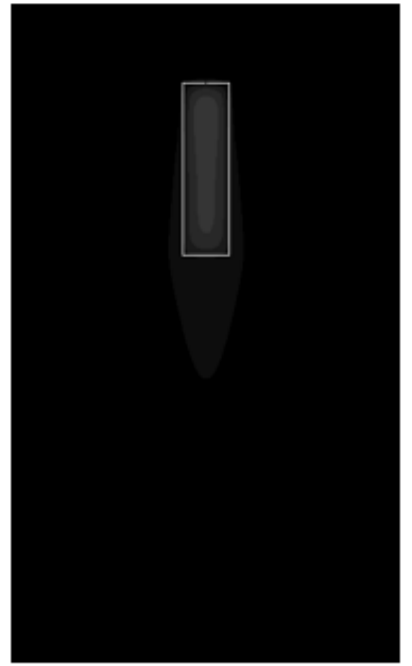

Figure 2: $\quad$ Temperature fields from computational fluid dynamics (CFD) for an inflow temperature of $600^{\circ} \mathrm{C}$ (a) at $74 \mathrm{~s}$, (b) $74 \mathrm{~s}$ (enlarged), (c) $199 \mathrm{~s}$, and (d) $395 \mathrm{~s}$. 
(a)

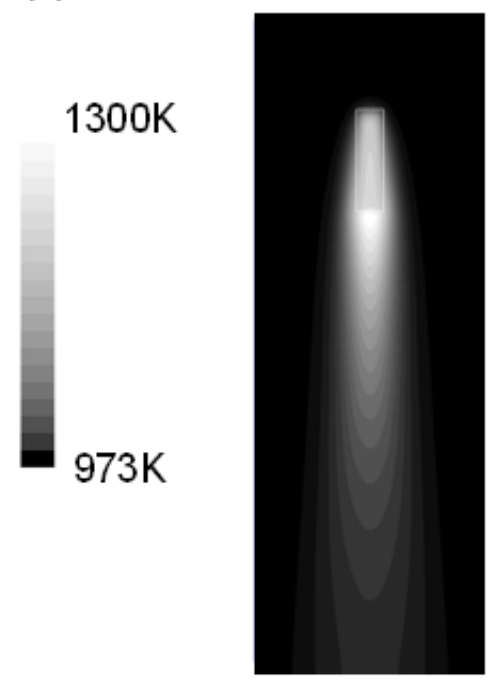

(c)

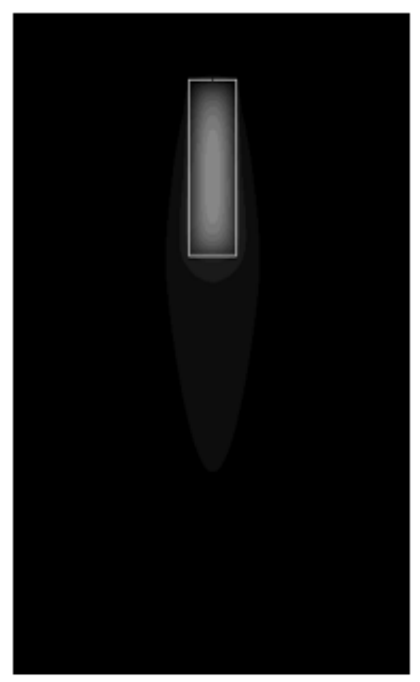

(b)

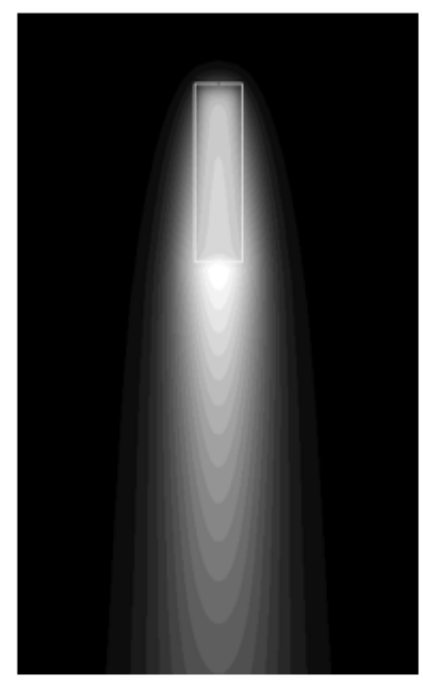

(d)

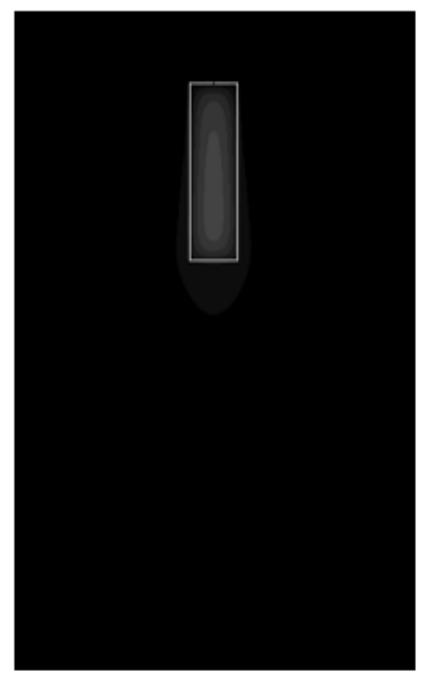

Figure 3: Temperature fields from computational fluid dynamics (CFD) for the inflow temperature of $700^{\circ} \mathrm{C}$ (a) at $12 \mathrm{~s}$, (b) $12 \mathrm{~s}$ (enlarged), (c) $68 \mathrm{~s}$, and (d) $249 \mathrm{~s}$. 
(a)

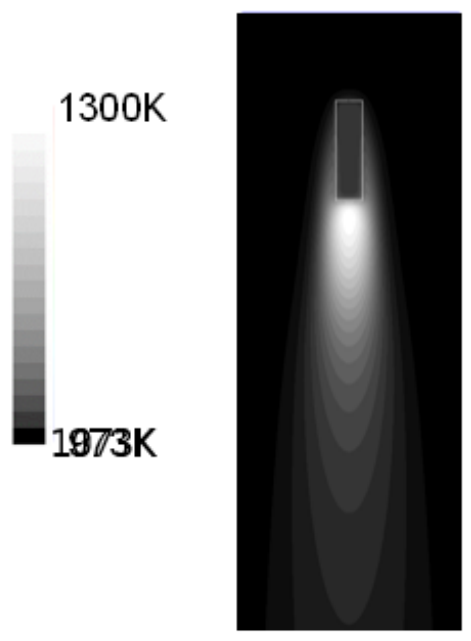

(c)

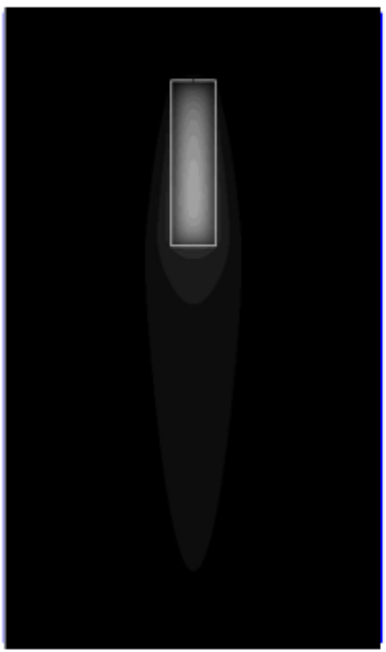

(b)

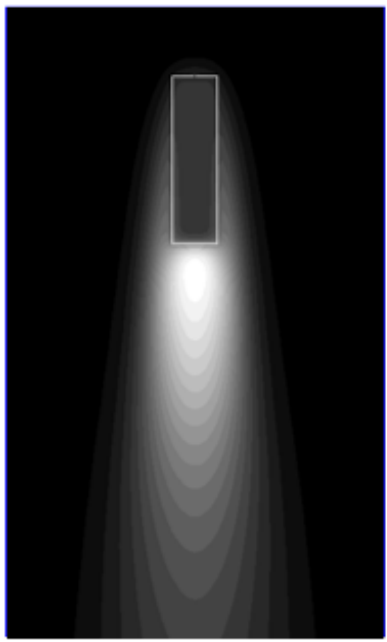

(d)

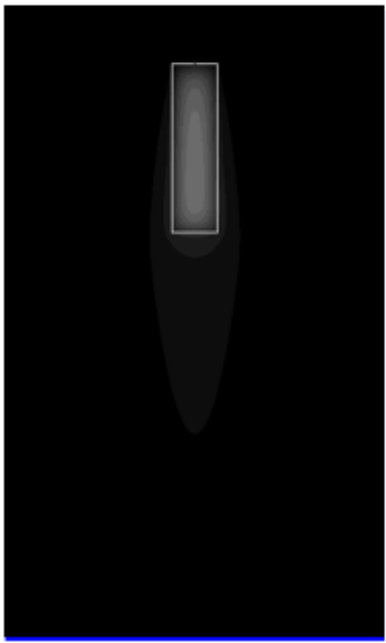

Figure 4: $\quad$ Temperature fields from computational fluid dynamics (CFD) for the inflow temperature of $800^{\circ} \mathrm{C}$ (a) at $3 \mathrm{~s}$, (b) $3 \mathrm{~s}$ (enlarged), (c) $68 \mathrm{~s}$, and (d) $202 \mathrm{~s}$. 


\section{Conclusions}

In the present study, a numerical simulation method for wood pellet combustion simulation was developed, and unsteady numerical simulation was performed for wood pellet combustion processes depending on atmospheric temperatures. The main results are summarized in the following points:

1) As a result of unsteady numerical simulation for combustion processes with atmospheric temperatures in the range of $500^{\circ} \mathrm{C}-800^{\circ} \mathrm{C}$, a flame was observed at $600^{\circ} \mathrm{C}, 700^{\circ} \mathrm{C}$, and $800^{\circ} \mathrm{C}$, but not at $500^{\circ} \mathrm{C}$.

2) Ignition occurred at the latter parts of the pellets as the velocity of the introduced air was decreased, and the locus of flame after ignition differed according to atmospheric temperature, while char was combusted throughout the pellet.

3) As the air temperature at the inlet increased, the combustion time for volatile matter was decreased due to faster evaporation of the volatile matter. Moreover, the combustion of char was more active; thus, the total combustion time was decreased.

\section{References}

[1] Kim, J.J. \& Kang, S.B., Performance Test and Flue Gas Characteristics of a 350 kW Wood Pellet Boiler, Proc. 2009 SAREK Summer Annual Meeting, pp. 167-171, 2009.

[2] Kang, S.B. et al., Performance Test and Flue Gas Characteristics of Domestic Wood Pellet Boilers, Proc. 2009 SAREK Summer Annual Meeting, pp. 569-573, 2009.

[3] Kang, S.B. et al., Performance Characteristics of Domestic Wood Pellet Boiler, Proc. 2010 KSME Fall Annual Meeting, pp. 3613-3616, 2010.

[4] Sim, B.S. et al., Combustion Characteristics of a Wood Pellet, Proc. 2010 KSME Fall Annual Meeting, pp. 3624-3629, 2010.

[5] Kang, S.B. et al., Performance Characteristics of Domestic Wood Pellet Boilers, Proc. 2011 SAREK Summer Annual Meeting, pp. 569-573, 2011.

[6] Benkoussas, B. et al., Modeling thermal degradation of woody fuel particles, International Journal of Thermal Sciences 46, pp. 319-327, 2007.

[7] Novozhilov, V. et al., Computational fluid dynamics modeling of wood combustion, Fire Safety Journal 27, pp. 69-84, 1996.

[8] Spearpoint, M.J. \& Quintiere, J.G., Predicting the burning of wood using an integral model, Combustion and Flame 123(3), pp. 308-325, 2000.

[9] Vijeu, R., et al., Dimensional modeling of wood pyrolysis using a nodal approach, Fuel 87, pp. 3292-3303, 2008. 